\title{
Una nueva copla sefardí antigua del ciclo de la reina Ester (Purim)*
}

\author{
Iacob M. Hassán, ל ז
}

CSIC, Madrid

\section{Precisiones SOBRe EL TítUlo}

Una nueva quiere decir, en este caso, una copla no conocida anteriormente, y no a priori que pertenezca al grupo de las coplas de Purim llamadas «nuevas». Copla sefardí quiere decir que está escrita en lengua sefardí (judeoespañol, ladino o como se prefiera denominarla... con tal que no sea judesmo). Copla antigua quiere decir que se escribió todavía en la misma época, si bien en las postrimerías, en la que se escribieron las demás coplas de Purim castizas. Copla como género literario lo tenemos de sobra definido: poema con ilación de contenido compuesto por un variable número de estrofas, todas con el mismo esquema estrófico ${ }^{1}$.

* [N. E. (E. Romero).- El presente artículo fue presentado como ponencia en la Thirteenth British Conference on Judeo-Spanish Studies celebrada en Londres (7-9 sept. 2003), pero, como muchas veces hizo a lo largo de su fecunda vida académica y, sin duda, acuciado por otras obligaciones, Jacob dejó pasar el tiempo y no lo entregó para su publicación en las Actas. El texto que a continuación doy a la publicación ha llegado a mis manos desprovisto de notas; ya que ignoro qué pensaba hacer al respecto, añado solamente las que, a mi buen entender, resultan imprescindibles. La edición de este artículo se ha llevado a cabo dentro del Proyecto de Investigación «Sefarad siglo XXI (2005-2007): Edición y estudio filológico de textos sefardíes» (MEC, DGS, HUM2005-01747/FILO).]

${ }^{1}$ Exposiciones más o menos amplias y detalladas del género han quedado expuestas en Elena ROMERO, «Las Coplas sefardíes: Categorías y estado de la cuestión», en Actas de las Jornadas de Estudios Sefardíes (Cáceres 1981) ps. 69-98, y en el de I. M. Hassán, «Un género castizo sefardí: Las Coplas», en Paloma Díaz MAS (ed.), Los sefardíes: Cultura y Literatura (San Sebastián: Univ. del País Vasco, 1987) ps. 103-123; vid. también Elena RoMERo, La creación literaria en lengua sefardí (Madrid: Fundación Mapfre, 1992) cap. 4 ps. 141-172 y la bibliografía de ps. 172-176; y recientemente el artículo de Ángel BERENGUER AMADOR, «El género literario de las coplas», en I. M. Hassán y R. IzQUierdo BENITO (coords.), Elena Romero (ed.), Sefardies: Literatura y lengua de una 
Y del ciclo de la reina Ester viene explicado en y por el paréntesis explicatorio: en una ordenación -erudita, académica- de todo el corpus de las coplas que conocemos (más o menos medio millar) según el referente cronológico de su contenido, observamos grupos de coplas que giran en torno a personajes o sucesos determinados (José el de Egipto, Moisés y el éxodo, los tanaítas, los asedios de Tiberíades, la revolución de los Jóvenes Turcos...); así es desde luego en el caso de las sucesos que nos cuenta el libro bíblico de Ester: las coplas que los cantan son, aunque no solo esas, las que corresponden a la ocasionalidad de Purim; y así, como «coplas de Purim», es como se conoce a las del ciclo de la reina Ester, no ya en la propia tradición sefardí sino también en general entre los eruditos que las han o las hemos estudiado.

\section{El CORPuS}

El corpus de las coplas de Purim -nuevas y viejas- lo fijó Moshe Attias en veinticinco en su canónico artículo en Sefunot (1958) 2; lo llamo «canónico» porque aunque Attias dedicó otros varios artículos al estudio de coplas de Purim (de Esmirna, de Salónica ${ }^{3}$ ), en este de 1958 es donde se preocupa de presentar y ordenar todos los materiales textuales y literarios llegados a su conocimiento,

nación dispersa (Cuenca: Ed. Univ. de Castilla-La Mancha, 2007) (en prensa). A ello hay que añadir el libro de Elena Romero, con la colaboración de I. M. HASSÁn y de L. CARRACEDo, Bibliografía analítica de ediciones de coplas sefardíes (Madrid: CSIC, 1992) [abrev. Baecs], en donde se catalogan doscientas sesenta y siete publicaciones que las contienen, en su mayoría aljamiadas y algunas en caracteres latinos, de entre 1700 y 1959; vid. allí especialmente la Introducción de I. M. Hassán (ps. 9-20). Puede verse asimismo una antología monográfica del género en Elena Romero, Primera selección de Coplas sefardíes (Córdoba: El Almendro, 1991), donde se publican una veintena de coplas, representativas de diversos grupos temáticos, de distintas épocas, de diferentes formas de transmisión -editadas, manuscritas y orales-y de sus dos áreas geográficas de difusión -la zona del Estrecho y la de los Balcanes-; vid. allí también la Introducción de I. M. HAssán (ps. 5-24). Sobre la métrica de las coplas vid. asimismo Elena RoMERo, «Formas estróficas de las coplas sefardíes», en F. Corriente y A. SÁenz-Badillos (eds.), Poesía estrófica, Actas del primer congreso internacional sobre poesía estrófica árabe y hebrea y sus paralelos romances (Madrid: Facultad de Filología, Univ. Complutense et al., 1991) ps. 259-278.

2 Moshe Atтias, «Judeo-Spanish “Coplas de Purim”» [en hebreo], Sefunot 2 (1958) ps. 331376 (+[16]): lista de ediciones en ps. 341-345.

3 En sus artículos «Jacob Jona - Wandering Minstrel of Salonica» [en hebreo], Sefunot 15 (1971-1981: The Book of Greek Jewry V) ps. 153-202: descripciones bibliográficas en ps. 171174 (+[ 15]-[16]); y «Coplas de Purim de Iźmir», Mahbereth 6/4-6 (57-58) (5717 / mar. 1957) ps. 62-64; «Pourim à Salonique» [en hebreo], Guinzach Saloniki (Archives Saloniciennes) A [= 1] (agosto 1961) ps. 55-73 ; y «Hag Purim», en Salonique:Ville Mère (1967) ps. 161-162. 
estableciendo un par de listas: la una, de cuarenta ediciones (pero alguna no es sino un manuscrito, que él supone «copia» de una edición perdida), y la otra, la ya mencionada de veinticinco coplas.

Este corpus de veinticinco coplas quedó reducido a veintidós al deducir tres, que no son sino sendas versiones de la Ketuḅá de Hamán (o de su hija), como dejé establecido en la revisión y ampliación del trabajo de Attias que constituyó mi tesis doctoral (1976) ${ }^{4}$. La explicación del error numérico de Attias es que no hubo tal «error» sino una diferencia de apreciación sobre lo que es «copla». Él tomó como determinante lo que se considera (o se consideraba, o se consideró) perteneciente al grupo de textos denominados «coplas de Purim» en la tradición viva sefardí, la de quienes las «usaron» (las escribieron y las cantaron); pero el análisis literario de esos tres textos muestra que no se trata de poemas estróficos sino de textos en prosa, aunque esa prosa sea prosa rimada (con algún que otro esporádico pareado o incluso terceto monorrimo); y aunque en las ediciones tengan una presentación tipográfica igual o muy semejante a la de las coplas, lo mismo que la tienen los otros pocos textos que ocasionalmente ocurren en ellas.

El corpus de veintidós (veinticinco menos tres) coplas sufrió una nueva merma con la publicación de la Bibliografía analítica de ediciones de coplas sefardíes [abrev. Baecs] (1992), pues ya entonces consideramos no ser copla uno de los textos de Attias (y Hassán): el que comienza «Aftir lašón / dolor de corazón» (Attias/Hassán XIII), un piyutico contrahecho más que contrafacto sobre el piyut hebreo «Aftir lašón / leel rišón» que aparece en unas pocas ediciones como remate de la versión en ellas contenida de la Ketubá de Hamán.

Pero parece que hubiéramos debido hacer lo mismo con otras dos textos, en los que me atrevo a decir que nos dejamos llevar por la inercia de considerarlos coplas a partir de la inicial consideración de Attias (y Hassán); dos textos que son cantigas o canciones (piyutines) pero no coplas según los criterios literarios y no catalográficos que rigen nuestro Catálogo de coplas sefardíes, reanudado con renovado brío tras una docena de años de latencia.

El uno es el que comienza «Y a mí me llamaban / Ḥayim Chiliḅí» (Attias/ Hassán XVII) y se titula Cantiga levantina en las pocas ediciones de Liorna en las que aparece (El llamado Hayim Chilibí en Baecs), que es un piyut macarrónico de hebreo y ladino sin ninguna rima en los versos impares de sus seis cuartetillas, que de ser copla no lo sería más de Purim que, por ejemplo, del ciclo del éxodo (de Pésah). Y el otro es el que se inicia «Oíd y tomad plaćer / qué

\footnotetext{
${ }^{4}$ Iacob M. Hassán, Las Coplas de Purim (Tesis Univ. Complutense: Madrid, 1976).
} 
quis̀o haćer Hamán el mamćer» (Attias/Hassán XXV), titulado Favor de Dios en Baecs, que tras ese espectacular comienzo ciertamente en consonancia con la poética de las coplas de Purim, se reduce a cinco estrofas sin asomo de fijeza en su esquema estrófico y ni siquiera en el número de versos por estrofa (seis, seis, siete, cuatro y cuatro). Una tercera copla está en entredicho, aunque las razones para excluirla no son por ahora determinantes: la que se inicia «Enmentaré Dio neemán / siempre fuiste padre raḥmán» (Attias/Hassán VII), versión sefardí del omnipresente piyut hebreo de Purim «Aźkir ḥasdé El neemán».

\section{Bibliografía DE LAS COPLAS DE PURIM CASTIZAS}

Las diecinueve (veinticinco menos tres menos tres) coplas de Purim son las veinte que presento en la lista que sigue; en la que tras un número de orden (que he procurado que sea cronológico), se recogen para cada copla, en campos separados por doble barra vertical $(\|)$ : en el primero, el título literario que recibe en Baecs, seguido (tras barra oblicua) del número (romano) en la lista de Attias (y Hassán), y cuando ha lugar, el título que recibe en ellas, que suele recoger el castizo que presentan en las ediciones. En el segundo, el íncipit en su formulación más frecuente (señalando entre paréntesis alguno ocasional), y tras dos puntos, su caracterización formal: el número de estrofas (de la copla o de sus varias versiones literarias cuando las tiene), el esquema estrófico (número de versos por estrofa) y el rímico: $\mathrm{M}$ abrevia rima monorrima y $\mathrm{Z}$ rima zejelesca, ambas en mayúscula o minúscula según sea largo o corto el verso (entre paréntesis <angulares $>$ y en cursiva la rima de vuelta), y 9p remite a la noneta octo-hexasílaba característica de las coplas de Purim; todo ello amén de, tras signo +, remisión sintética al estribillo cuando lo hay (que me veo obligado a llamar «refrán» para que su abreviatura «refr.» no se confunda con la de estrofa). En el tercer campo se recogen los datos de autoría en los casos en que se conocen, y la fuente de donde proceden (constancia editorial en portada o cabecera, acróstico, etc.). En párrafo aparte se señalan el número de ediciones conocidas hasta la fecha, que hemos siempre de considerar provisional.

1 Los milagros de Purim / H(A) IX $\approx \|$ «Y fue en días de el rey Aḥašveróš / siervo de Nebujadneŝar y hermano de Toros / ...»: (A)53 o (B)72 o (C)30 estrs. $4 \mathrm{Z}<n o>\|$ Autor Abraham Toledo ¿Escopia? (acr.).

9 eds. (de ca. 1700 a 1884) +9 ms. (=18).

2 La historia de Amán y Mardoqueo / H(A) I Coplas de Purim \| «Enpezar quero a contar / hechas del Dio alto / ...»: (A)111 o (B)112 o (C)112 estrs. 9p \| Autor 
Abraham de Fez / ¿de Pas? (port.); Abraham madpís ['impresor'] (acr.).

29 eds. (de ca. 1720 a 1923$)+8$ ms. (= 37).

3 Manjares y dádivas de Purim / H(A) II Ticún se 'udat Purim \| «Con ayuda del Dio alto / que no mos haga nada falto / ...»: (A)85(65,31) о (B)50 o (C) 75 estrs. $4 \mathrm{z}<-e r>$ (+ refr. Viva) $\|$ Autor Ya'acob 'Usiel (cab.). 26 eds. (de 1739 a 1932$)+8$ ms. $(=34)$.

4 La historia de Purim / H(A) V $\approx \|$ «Oíd, señores, este nes y maravilla / que aconteció a la judería / ...»: (A)127 o (B)134 estrs. 4Z <no> \| Autor Šemuel b. Yișḥac Araña (acr.). 3 eds. (de 1778 a 1923$)+3$ ms. (= 6).

5 Breve historia de Purim / $\mathrm{H}(\mathrm{A}) \mathrm{VI}=\|$ «Un rey grande y enšalžado / Aḥašveróš era nombrado / ...»: (A)41 o (B)40 estrs. 4z <-ta> + refr. Venid / Quen $\|$ Autor ignoto.

8 eds. (de 1778 a 1884$)+4$ ms. $(=12)$.

6 El triunfo de Mardoqueo / H(A) VIII Triunfo de Mordejay || «Enpezar quero a contar / lo que aconteció en adar / ...»: (A)46 o (B)36 o (C)28 o (D)23 estrs. $4 \mathrm{z}<-o ́>+$ refr. Viva / Hoy $\|$ Autor ignoto. 3 eds. (de 1778 a 1884$)+5$ ms. $(=8)$.

- Favor de Dios / H(A) XXV = $\|$ «Oíd y tomad placeer / qué quis̀o haćer Hamán el mamćer / ...»: 5 estrs. 6,6,7,4,4 \| Autor ignoto.

$$
2 \text { eds. (de } 1778 \text { a } 1923)+0 \text { ms. }(=1) \text {. }
$$

7 La intercesión de Ester / H(A) III Cantiga de Purim \| «Con gran placeer, señores, / yo vos quiero contar / ...»: 12 estrs. 8abab(cc)cxd <Yisrael $\|$ Autor ignoto.

2 eds. (de 1782 a 1820$)+6$ ms. $(=8)$.

8 Gozo y alegría de Purim / H(A) X Mucho gozo y alegría \| «Mucho gozo y alegría / hagamos en este día / ...»: 17 estrs. 4z <-dor> + refr. Hodú \| Autor Mordejay Yaír Melul (Sr).

1 ed. (de 1782) +2 ms. $(=3)$.

- El llamado Hayim Chilibí / H(A) XVII Cantiga levantina $\|$ «Y a mí me llamaban / Hayim Chiliḅí / ...»: 6 estrs. 4aı́bí + refr. [hb] \| Autor ignoto.

2 eds. (de 1782 a 1840$)+2$ ms. (= 4).

9 El ajuar de Amán / H(A) XVIII El ajuar \| «Enpezaré y diré la jugar de Hamán / y al Dio alabaré que es muy raḥmán / ...»: 32 estrs. 3M + refr. yš" $v \|$ Autor ignoto.

5 eds. (de 1797 a 1884$)+1$ ms. $(=6)$. 
10 La caída de Amán / H(A) XI $\approx \|$ «Enpezaré a contar / una grande hestoria / ...»: 39 estrs. 9p || Autor ¿Azecri? Asquenazi (acr.).

18 eds. (de 1798 a 1934) +5 ms. (= 23).

11 El testamento de Amán / H(A) XII El testamento = La ŝavaá $\|$ («Bendicho sea el Dio / pues que tal Purim mos dio / ...») «Un día antes que muriera / llamó a toda su parentera / ...»: (25)22 estrs. 4z <Purim $>$ (+ refr. Viva) $\|$ Autor ignoto.

20 eds. (de 1798 a 1932$)+5$ ms. (=25).

* / H(A) XIII Aftir lašón = $\|$ «Aftir lašón / dolor de corazón / ...»: 6 estrs. ¿3/4? ¿m/z? || Autor ignoto.

12 La celebración de Purim / H(A) XIX $\approx \|$ «Alabar quero al Dio / con tañer y cante / ...»: 28(27,29) estrs. 9p \|| Autor Sa ‘adí Haleví (port. acr.).

11 eds. (de 1856 a 1935$)+1$ ms. $(=12)$.

13 El espejo de Amán / H(A) XXI = \| «Enpezaré y contaré cada uno de sus miembros / en que se atrivió el gursús facha de pero / ...»: 21 estrs. $4 \mathrm{Z}<-$ ró> (+ refr. $\left.y \check{s}^{\prime \prime} v\right) \|$ Autor Sa adí Haleví (port. acr.).

10 eds. (de 1856 a 1935$)+1$ ms. (= 11).

14 El daledale de Purim / H(A) XX Dale, dale \| «Se acodren de los hijicos / tanto probes, tanto ricos / ...»: 9 estrs. $4 \mathrm{z}<-l e>(+$ refr. [tc.]) \| Autor Sa'adí Haleví (port. acr.).

10 eds. (de 1856 a 1935$)+1$ ms. (= 11$)$.

15 El Dio neemán / H(A) VII = \| «Enmentaré Dio neemán / siempre fuiste padre raḥmán / ...»: 5 estr. 4 ¿z? -(n)í \| Autor ignoto.

3 eds. (de 1860 a 1932$)+1$ ms. $(=4)$.

16 El casamiento de Amán / H(A) XIV El casamiento \| («Bendicho sea el Dio / pues que tal Purim mos dio / ...») «Estando yo en un pensamiento / en cośa que lo llevaba el viento / ...»: (25)22 estrs. $4 \mathrm{Z}<(-)$ yo $>\|$ Autor ignoto. 4 eds. (de 1861 a 1932$)+0$ ms. $(=4)$.

17 La endicha de tía Bicha / H(A) XVI La endecha || «Apañadvos las hermanas / y haćed grandes oínas / ...»: 14 estrs. 4z <-ió> $\|$ Autor ignoto. 4 eds. (de 1861 a 1895$)+0$ ms. $(=4)$.

18 El retrato de Zeres / H(A) XXII $\approx \|$ «Estas desgracias de la babú no valen pará / no sea que me haga burla el que las sentirá / ...»: 21 estrs. $4 Z<-r a(h)>$ + refr. $y \breve{s}^{\prime \prime} v$ [fm.] $\|$ Autor Sa 'adí Haleví (port. acr.).

9 eds. (de 1862 a 1935) +1 ms. (=10). 
19 Nueva historia de Purim / H(A) XXIII = || «Alabaré al Dio alto / tanto noche como día / ...»: 50 estrs. 4abab || Autor Šelomó Morduj (port. acr.).

1 ed. (de 1869) +0 ms. (=1).

20 La bebienda de Purim / H(A) no \| «Este día es alegría / para toda la judería / ...»: 21 estrs. $4 \mathrm{z}<$ Purim $>+\mathrm{E}$-ado $\|$ Autor Yehudá Castel (port.).

1 ed. (de 1896) +0 ms. $(=1)$.

\section{Estrofismo}

Podemos observar que de las diecinueve (veinte menos la última) coplas, trece (una de ellas dudosa) están en estrofa de cuatro versos con rima zejelesca de vuelta, cinco en verso largo (1 Milagros, 4 Historia, 13 Espejo, 16 Casamiento y 18 Retrato) y ocho en verso corto (3 Manjares, 5 Breve historia, 6 Triunfo, 8 Gozo y alegría, 11 Testamento, 14 Daledale, 15 Dio neemán [esta es la dudosa] y 17 Endicha); y aun podrían ser catorce si consideramos que el estribillo hebraico «yimah šemó veźijró» que sigue al terceto monorrimo en Ajuar (9) sea verso de vuelta de pie quebrado. Ello supone una aplastante mayoría sobre las escasas tres coplas en noneta octo-hexasílaba (2 Historia de Amán, 10 Caída y 12 Celebración), esquema formal que la tradición, y tras ella los eruditos, han venido a considerar como la estrofa por antonomasia de las coplas de Purim; y no digamos sobre la esporádica Nueva historia (19) en cuarteta de rima alterna, y sobre la singularísima Intercesión (7) en estrofa de ocho versos con pie quebrado interior y rima de vuelta, singular también por ser la única propia de la zona del Estrecho (y yo creo, por razones de léxico y de estilo, que allí compuesta).

\section{AutoríA}

En cuanto a la autoría, conocemos el nombre de los autores de cinco coplas antiguas (1 Milagros, 2 Historia de Amán, 3 Manjares, 4 Historia y 8 Gozo y alegría) y de cinco modernas (12 Celebración, 13 Espejo, 14 Daledale, 18 Retrato y 19 Nueva historia), aunque de algunos de esos autores -Abraham de Fez, Ya'acob Uśiel y Šemuel Araña- lo único que podamos afirmar con certeza es que se llamaban así. 


\section{LAS EDICIONES}

Antes de tratar de la cronología de las coplas conviene dedicar una cierta atención a las ediciones. Limitándome ahora a las coplas publicadas como libro independiente y no a la inclusión de coplas en publicaciones periódicas (que presentan una problemática diferente), conocemos hoy sesenta y nueve ediciones diferentes de coplas de Purim, publicadas entre ca. 1700 y 1935, seis de las cuales no constan en Baecs por haberse descubierto o identificado con posterioridad a 1992. Para la datación de las coplas no tengo en cuenta las versiones manuscritas por la dificultad, a menudo insalvable, de determinar la fecha de la puesta por escrito de un texto incluso en manuscritos datados.

La gran mayoría de las ediciones son menudos folleticos a modo de pliegos de cordel, que contienen coplas de Purim (entre una y seis) solamente o con adición de unos pocos textos relacionados con ellas; estos son: tres cancioncillas de Purim en (judeo)italiano arabizado («Ual viba ual viba / il nostro Burino» llamado Cantiga de Purim a la moresca, «Montato al testa il fantasía» llamado Historia de Purim a la moresca, y «Carnovale non ten andare» llamado Canzoneta en italiano supra un pródigo y un avaro), los tres en ediciones de Liorna; y en las demás, unos pocos en hebreo: algunos piyutim, en especial la bacašá del sábado Źajor «Aźkir ḥasdé El neemán» de Abraham Ḥayún, y la parodia de la haškabá ('responso') de Amán que comienza: «Má rab nicmatejá ašer ŝafanta leoyebeja» ['cuán grande es tu venganza que has reservado a tus enemigos'], versus hb. «Má rab tubejá ašer ŝafanta lireeja» ['cuán grande es el bien que has reservado a quienes te temen']».

Se titulan los folletos precisamente Coplas (o Conplas o Complas, y en un caso -en una edición en caracteres latinos-Canción) con el determinante de Purim, y a veces con el determinante adicional viejas o muevas (о nuevas) antes o después de coplas; en un caso (Constantinopla 1778) el único determinante de Coplas no es de Purim sino nuevas. Unas pocas aparecen tituladas simplemente Coplas; pero no podemos asegurar que se titularan realmente así, pues se trata en todos los casos de ediciones conocidas a través de un ejemplar único manco de portada y tituladas por los bibliógrafos a partir del folio editorial de páginas interiores.

De esta norma general se apartan una minoría de ediciones (seis) en las que las coplas de Purim aparecen como sección con epígrafe propio dentro de un libro más amplio dedicado a Purim (Alegría de Purim [Liorna 1875 y 1902]) o a la traducción de textos litúrgicos y paralitúrgicos hebreos (Traduction libera [Cracovia 1934]), o en un piyutario o colección de coplas y piyutim para ocasio- 
nes diversas (Yaguel Ya'acob [Jerusalén 1885], Col źimrá [Jerusalén 1896]), o bien otras en que una copla de Purim aparece imprevisiblemente en un libro de coplas de otra categoría (Tobá tojáhat megulá [Esmirna 1739] de Hayim YomTob Magula). De la norma se salen también la escasa decena de ediciones exclusivas de coplas de Purim pero tituladas no de modo genérico sino según el título de una de las coplas que contiene (la única o la inicial), o bien -y ello es casi la norma en ediciones de Liorna- con un título general y no específico (Cantares y alabaciones [Liorna 1820]) o retórico (Soba' semaḥot [Liorna 1782], Salmé simhá [Liorna 1792]) porque la especificidad de Purim donde consta es en el subtítulo (o «Compendio de la alegría», o «La alegría cumplida» etc.).

Eso cuando podemos leer el título. No menos de un tercio de las ediciones nos han llegado en ejemplares carentes de portada (casi siempre únicos) o sin pie editorial, de modo que su lugar y fecha de edición no son más que probables. Aun así, podemos afirmar que más de la mitad de las ediciones son de Salónica (36); un número notable tienen también Liorna (10) y Constantinopla (9); con menos siguen Esmirna (5), Jerusalén (4), Belgrado (3), Viena y Amsterdam ( 2 ambas); y cierran la lista Alejandría, Sarajevo y Craiova (1 cada una). Siete ediciones están en caracteres latinos: de las antiguas, las dos de Amsterdam y dos antiguas de Liorna, las cuatro con ortografía española de la época; y de las modernas, la de Sarajevo, con ortografía del serbocroata, la de Craiova, con ortografía rumana, y la de Alejandría con ortografía a la franca estándar (o sea, más bien anárquica). Ni que decir tiene que todas las demás son aljamiadas, siendo relativamente abundantes las vocalizadas, total o parcialmente.

He mencionado que unas pocas de las ediciones que hoy conocemos no las conocíamos hace una docena de años cuando se publicó Baecs. Seguro que de aquí a unos años, no sé cuántos, nuestro conocimiento del corpus de ediciones habrá aumentado: debido al hallazgo de ediciones hasta ahora desconocidas (como ha ocurrido recientemente con sendas ediciones de coplas de Pésah y de Šabu 'ot ${ }^{5}$ ), o siquiera de algunas de las hoy perdidas pero de cuya existencia nos da testimonio algún bibliógrafo fidedigno que la viera (Conplas muevas de Purim [Salónica 1858 y Salónica 1868]), o bien de otras que sabemos positivamente que existieron por testimonio interno de alguna edición posterior. De estas últimas hubo al menos dos.

La primera es una edición de Salónica 1821 titulada -seguramente-Conplas de Purim, cuya existencia nos documenta el texto de portada de la del mismo tí-

\footnotetext{
5 Vid., por ejemplo, el artículo de Ignacio Ceballos Viro, «Una nueva copla de Šabu 'ot: Los judíos en el Sinaí», Sefarad 65 (2005) ps. 41-64.
}

SEFARAD, vol. 67:2, julio-diciembre 2007, págs. 415-435. ISSN 00037-0894 
tulo de Belgrado 1861, que dice (en hebreo): 'Estas son las impresas en Salónica en el año $=1821$ y he aquí que ahora se imprime por segunda vez ...'; mención que se repite con el único cambio de 'tercera vez' en la edición de Belgrado 1889 y en las gemelas de Viena 1892 y Esmirna 1892. La segunda no encontrada es la de Sa'adí Haleví de Salónica 1855 titulada-seguramente-Conplas muevas de Purim, de la que el propio editor coplero nos dice en portada de su edición del mismo título del año siguiente (Salónica 1856):

«Siendo agora un año se hićieron con aĝilé [tc. 'precipitación'] y salieron yalin cat [tc. 'imperfectamente', ¿'en hojas sueltas'?], me pareció monasup [tc. 'conveniente'] ajustarlas que no quedaran sacat ['defectuosas'].

He querido mencionarlas para que cualquiera de los lectores que pueda tener noticia de algún ejemplar, sepa que es preciosa joya bibliográfica (y por favor, me dé fotocopia).

De las ediciones que sí nos han llegado, interés especial tienen aquellas pocas que nos documentan sobre la fecha de composición de una copla o sobre el corpus de coplas existente en el momento de su publicación; a ellas, y solo a ellas, voy aquí a referirme. La pareja de ediciones Coplas con Ticún se 'udat Purim y la antes citada Coplas nuevas, que Mošé Cid y su socio Yošúa' Baruj publicaron en 1778 en la imprenta de Šemuel Ašquenaźí (Constantinopla), recogen hasta seis coplas; las mismas que, añadiendo otras dos, recogen también las dos ediciones gemelas Soba' semahot y su complementaria Salmé simhá que a los pocos años publicó en Liorna Mordejay Yaír Melul en honor de su homónimo nieto (1782 y 1792): los textos introductorios nos permiten asegurar que entrambas parejas nos han transmitido la totalidad del corpus de coplas de Purim que circulaba en aquellos años. Bastantes décadas después, en la de los cincuenta del siglo XIX, el coplero y periodista Sa 'adí Haleví comienza en Salónica la larga serie de ediciones de sus propias coplas (ahora nuevas): la perdida edición de 1855 , o en su defecto las de 1856 y 1862, nos indican cuándo se compusieron sus cuatro coplas nuevas. A finales de la década siguiente Yiŝhạac Escapa con sus socios Mercado Hayim Ánĝel y Abraham David Bitrán publica Complas muevas de Purim (Salónica 1869), que contiene la única versión impresa conocida de la copla de Šelomó Morduj: la edición sin embargo no nos ilustra sobre su fecha de composición, pues el texto de portada dice «ditas coplas de Purim se toparon escritas ... miźemán cadmón ['desde tiempo antiguo']».

Una docena de ediciones llevan en el título el determinante «nuevas» (o «muevas»), que en sí mismo no quiere decir nada en cuanto al tiempo de su 
composición, pues la ya mencionada edición de Constantinopla 1778 así titulada contiene las coplas Triunfo (6), Breve historia (5), Milagros (1) y Historia de Purim (4), que son de las más antiguas (comienzos del siglo XVIII) y una seguramente la más antigua de todas. Frente a ellas, en otras cinco el determinante cronológico es «viejas» (o «al uso viejo»), pero las ediciones de Salónica 1866 y 1885 de tal título contienen las coplas Caída (10) y Testamento (11) que datan de finales del siglo XVIII. Tales determinantes indican más bien que los autores, los editores y quizás también el público receptor las sentían como tales, como ocurrió en efecto a partir de mediados del siglo XIX con las coplas «nuevas» de Sa 'adí Haleví Celebración (12), Espejo (13), Daledale (14) y Retrato (18); o bien que los editores quisieron presentarlas como novedad las nuevas o como venerables las viejas, como cuando el editor de ¿Viena? ca. 1890 al publicar coplas realmente antiguas lo que dice es: «siendo 40 años que no se estampan».

Lo que viene a resultar de todo ello, combinando el testimonio de las ediciones que nos han llegado con el que han querido darnos los editores, es que de las coplas antiguas, tres (1 Milagros, 2 Historia de Amán y 3 Manjares) estaban ya compuestas en las primeras décadas del siglo XVIII, otras cinco (4 Historia de Purim, 5 Breve historia, 6 Triunfo y 7 Intercesión) lo estaban hacia mediados de la segunda mitad del siglo, y tres más (9 Ajuar, 10 Caída y 11 Testamento) en la última década. Medio siglo transcurre sin que -a juzgar por las apariencias- se componga ninguna nueva copla de Purim, hasta que a partir del ecuador del siglo XIX aparecen no solo las cuatro de Sa 'adí Haleví (12 Celebración, 13 Espejo, 14 Daledale y 18 Retrato) sino otras tres de autor anónimo y difusión limitada (15 Dio neemán, 16 Casamiento y 17 Endicha). Y a finales de la década de los sesenta se compone, o se exhuma, la última copla de Purim castiza de la que teníamos noticia: la nueva/vieja Nueva historia (19).

\section{COPLAS «NOVIÍSIMAS» DE PURIM: UN PRIMER MUESTREO BIBLIOGRÁFICO}

A partir de entonces se siguen reeditando coplas anteriores, mayoritariamente las «muevas» de Sa 'adí Haleví. Pero el gusto cambia e incluso estas se hacen añejas. Y la creatividad parece refugiarse, hasta el final de la tercera década del siglo xx, en unas -más que «nuevas»- «novísimas» coplas, que casi pertenecen ya a la categoría de coplas «del felec» (o de actualidad) y de Purim tienen sólo la ocasionalidad de su publicación o a lo sumo alguna reminiscencia textual pero no el contenido. Son las cinco que constan en la siguiente lista apendicular: 
A Los nuevos ricos / H(A) no $\|$ «Hoy no quedó más Purim / ni abrir las manos / ...»: 8 estrs. 9p \|| Autor Alexandro Péreẑ (port.).

1 ed. (de ca.1920) +0 ms. $(=1)$.

B El Purim de antaño I / H(A) no \| «La fiesta del sućio Amán / y Ester la brava / ...: 6 estrs. 9p \|| Autor Alexandro Péreẑ (port.).

1 ed. (de 1922) +0 ms. $(=1)$.

C Las promesas de los gobernantes / H(A) no \| «En Purim cada jidió / cantaba y reía / ...: 10 estr. 9p \| Autor Alexandro Péreẑ (port.).

1 ed. (de 1922) +0 ms. (= 1$)$.

D El Purim sin dinero / H(A) no \| «Ónde stá aquel Purim / sin gailet ni dertes / ...: 8 estrs. 9p \|| Autor Alexandro Péreẑ (port.).

1 ed. (de 1929) + 0 ms. $(=1)$.

E El Purim de antaño II / H(A) no || «La fiesta del sućio Amán / y Ester la brava / ...: 9 estrs. 9p || Autor ignoto.

1 ed. (de ca.1930) +0 ms. $(=1)$,

que elevan a setenta y cuatro el número de ediciones conocidas. No he incluido en ella las incontables que aparecen en la prensa periódica, casi cada año en tiempo de Purim, sino solo aquellas que aparecen en folletos que por su título o texto de portada harían pensar que contienen coplas castizas; y en la que se percibe que quien domina el novísimo género es el novísimo coplero Alexandro Péreẑ. Como con toda nitidez y palabras mejores que las mías nos dice él mismo como editor del periódico El Chaquetón 2/41 (Salónica 1921) al presentarnos el texto de una de estas coplas:

Por non mancar al uśo que teníamos antes del fuego de non dejar pasar Purim sin haćer complas yindo de acodro con la situación, topimos monasup de haćer hogaño también una chica compla del felec para que los lectores las canten esta noche en lugar de las complas de ḥan Sadí que ya se hićieron viejas y ya pasaron de moda. / Se cantan al son de «Alabar quiero al Dio»,

dando como punto de referencia la más modernas de las tres coplas castizas en noneta octo-hexasílaba distintiva de las coplas de Purim (que ahora vemos que es más bien, de por Purim). 


\section{DifUSIÓN}

Volviendo a las coplas castizas, vemos que su difusión (o popularidad) es muy desigual y que el número de ediciones en las que aparece cada una oscila entre veintinueve (2 Historia de Amán, seguida de cerca por 3 Manjares) y una (8 Gozo y alegría y 19 Nueva historia). Si combinamos estos datos con la fecha de composición vemos que algunas coplas antiguas cayeron en el olvido, mientras que otras se han mantenido incólumes en la memoria a lo largo de los años.

¿Y la primera copla de Purim cuándo se escribió? Los Manjares (3) parece que hubo de componerse no mucho antes de su primera edición conocida en Tobá tojáhat megulá (Esmirna 1739); pero quizás tengamos que adelantar la fecha varias décadas si se comprueba que su autor $\mathrm{Ya}$ 'acob 'Uśiel sea el mismo Jacob Usiel que actuó en Amsterdam en pleno siglo XVII. Por su contenido folclórico descriptiva del deleitoso banquete de Purim, hace pensar -como señaló Attias- que se escribiría como complemento de una copla anterior que relatara la milagrosa historia, que él supuso que fuera la Historia de Amán (2), escrita en la noneta octo-hexasílaba propia de las coplas de Purim y obra del denominado en algunas ediciones antiguas Abraham de Fez, a quien intenta -bien que forzadamente- identificar con Abraham Toledo, el autor de la larga copla de Las hazañas de José (o Coplas de Yosef haŝaḍic); pero no puede excluirse que «de Fez» sea una mala lectura por «de Pas» y que el autor no sea de origen norteafricano sino -también éste- de los Países Bajos; ni desdeñar que la palabra que sigue a Abraham en el acróstico estrófico, inseguro por no ser la príncipe la edición más antigua que conocemos, podría también leerse madpís (hb. 'impresor'), que nos deja tan inciertos como estábamos.

Sea como fuere, lo cierto es que la edición con seguridad más antigua de coplas de Purim llegada a nuestras manos no contiene ninguna de las dos mencionadas coplas sino Milagros (1), esta sí con certeza de Abraham Toledo, como lo muestra la lectura sagazmente restaurada por Attias del acróstico estrófico, a lo que yo he creído poder añadir, no se si sagaz o fantásticamente, lo que quizás pueda leerse como «de Escopia».

Pero la cosa no es tan simple. Esa más antigua edición de coplas de Purim que contiene la copla Milagros (1) es una en caracteres latinos de Amsterdam conservada en ejemplar único sin portada, en lugar de la cual hay una inscripción manuscrita que dice «Micamoca burlesco / compuesto por Joseph Benjaes de Constantina», que es imposible determinar si recoge datos que constaran en la perdida portada impresa o si se trata de invención del manuscriba: lo primero 
lo hace suponer el que Joseph Benjaes aparezca como firmante de la primera página, que contiene una Dedicatoria a Manuel de Belmonte, «Barón de Belmonte y conde Palatino»; éste no es otro que Isaac Nunes Belmonte, que fue elevado a la baronía en 1693 y murió en 1705, lo cual lleva a Dov Cohen a fijar 1700 como año de edición, y seguramente estará en lo cierto. Pero salvando su indiscutido magisterio bibliográfico, el que una edición de 1694 de la traducción española por Isabel Correa de El pastor Fido de Giovanni Battista Guarini incluya una dedicatoria a Belmonte con la misma fórmula de «Barón de Belmonte, Conde Palatino» (aquí con la adición de «y Regente de su Magestad Cathólica») mientras que en ediciones de Miguel (Daniel Leví) de Barrios de 1684 (Quinta de ducados en campaña de honoríficas dignidades) y 1686 (Espejo de la opulenta y arqueada Amsterdam) se le aluda como «don» a secas o lo más como «el illustrissimo señor don» permite pensar que fuera en aquellos años inmediatos a su nombramiento cuando fuera de buen tono mencionarlo como barón y conde, y que en consecuencia, la edición Micamoca burlesco, o como quiera que fuese su título original, debamos datarla en la última década del siglo XVII, o como dice Harm den Boer, «probablemente de finales del s. XVII, principios del XVIII» ${ }^{6}$.

El título manuscrito tiene como referente cierto el piyut hebreo «Mi kamoja» de Yehudá Haleví, que ha sido y sigue siendo entre los sefardíes el piyut hebreo de Purim por antonomasia: no tiene por ello nada de extraño que en ladino la primera copla fuera una parodia burlesca del mismo piyut. Parodia con mucho de contrafactum, pues hay que recordar que la copla Milagros (1) está compuesta en cuartetos de rima zejelesca con vuelta en no, a imitación de la vuelta en $l o$ (que en este caso no es 'no' sino 'a él') del piyut hebreo. Se explica así también que de las antes vistas catorce coplas de Purim en estrofa zejelesca, casi la mitad (seis) tengan vuelta terminada en (-)ó.

Pero hay más. En el pasaje cuando le llevan a la reina Vaští el recado de que acuda desnuda al convite del rey Ahašveróš, hay en esta primera edición de Amsterdam un verso que dice: «dixole desnudavos Reyna que ansí mandò el Rey sino vosgarvo» (10b), cuyas ininteligibles palabras finales han sido sustituidas en la posterior reedición de Liorna 1767 (Istoria de Amán y Mordohay) por «... mandò el Rey que vas sin manto», que inciden en el motivo de la desnudez repitiéndolo de modo superfluo, pues está ya explicitado en el verso anterior; pero la difícil formulación de Benjaes es posible que dé testimonio de la formulación original si enmendamos y meldamos «que ansí mandó el rey: si no,

\footnotetext{
${ }^{6}$ En su libro La literatura hispano-portuguesa de los sefardies de Amsterdam en su contexto histórico-social (ss. XVII y XVIII) (Amsterdam: Univ., Faculteit der Letteren, 1992) p. 379.

Sefarad, vol. 67:2, julio-diciembre 2007, págs. 415-435. ISSN 0037-0894
} 
vos harvo»; lo cual vendría a querer decir -ahora en contra de la «Amsterdam connection» antes propuesta- que lo que habría hecho Benjaes hubiera sido poner en cristiano (en letras latinas quiero decir) una anterior versión aljamiada de Oriente, de la cual habría trascrito toscamente la het de harvo mediante $g$. Si en verdad fue así la cosa, resultaría que hubo al menos una edición aljamiada de coplas de Purim del siglo XVII, reforzando la tesis de Avner Perez sobre la circulación de ediciones de las Coplas de Yosef haŝạ̣ic en dicho siglo ${ }^{7}$.

\section{UNA NUEVA COPLA CASTIZA}

Del examen de las ediciones de coplas de Purim descubiertas en los últimos años resulta que, en contra del convencimiento de todos los que nos hemos ocupado de la cuestión, la creatividad de coplas no novísimas perduró al menos otras tres décadas después de la edición de 1869 de la Nueva historia (19), ya que de 1896 es la edición del piyutario multilingüe hierosolimitano Séfer Col źimrá ['La voz de la zambra'] del joven (entiéndase 'soltero') Yehudá Castel, quien nos ofrece (h. 25ab) la vinícola copla, probablemente suya, que he denominado La bebienda de Purim, compuesta al estilo de las mejores coplas antiguas -sean viejas o nuevas- de Purim.

El libro en el que se publicó es una colección de piyutim para diferentes ocasiones festivas, al estilo del Yaguel Ya 'acob de Burlá (Jerusalén 1885) y otros semejantes, de su mismo editor Šemuel Haleví Zuckerman pero con la diferencia esencial de que además de textos en hebreo tiene varios en judeopersa; y la accidental (y eso sí que es un novísimo milagro de Purim) de que no llegara al conocimiento de Attias, pues él conoció la segunda edición (Jerusalén 1901) en la que no aparece nuestra copla, y a pesar de que en la introducción dice Castel que su contenido difiere del de la primera de 1896 (y su extensión, hay que añadir, pues esta segunda edición tiene ochenta y dos hojas frente a las treinta y dos de la primera), no llegó a sospechar que hubiera un texto en ladino en lo que juzgó como una colección de piyutim en judeobujárico y menos que ese texto fuera justamente una copla de Purim. No es ya milagroso sino completamente natural que contando yo con tan eruditos colegas y devotos amigos como Edwin Seroussi, Rivka Havassy, Dov Cohen y Shmuel Refael, hayan entre los cuatro traído la copla a mi conocimiento.

${ }^{7}$ Vid. su libro Abraham Toledo, "Las coplas de Yosef Ha-Tsadik": A multilateral critical comparative study and examination of the place of the work in the context of Ladino literature (Jerusalem et al.: Ben-Zvi Institute et al., 2005). 
El texto ocupa las dos caras de la hoja 25 del librito. En letra cuadrada y con la primera palabra de cada estrofa en cuerpo mayor, está encabezado por el epígrafe «Complas de Purim» y encabezado por el laḥan «Amán chiquiroña», que ha resistido hasta el momento todos nuestros intentos de identificación y de desciframiento (espero sugerencias) ${ }^{8}$. Está formado por veintiuna cuartetas de rima zejelesca con vuelta en Purim, que vuelve al estribillo «Hamán fue atado, / también enforcado», cuyo inicio se repite tras todas las estrofas. Y dice así:

\section{La bebienda de Purim}

[25a] 1 Este día es alegriya para toda la juderiya porque muncha maravilla mos hiźo el Dio en Purim.

Hamán fue atado, también enforcado.

2 Después de seer vendidos todos los judiós queridos súpito fuimos regmidos en este día de Purim.

Hamán fue vejú'.

3 Cada uno que es judió que alabe a su Dio, que la estrella le cayó de Hamán en Purim.

Hamán fue.

4 Los većinos que se ajuunten, no se anojen ni se apunten ${ }^{9}$, que se asenten y que conten este nes de Purim.

Hamán fue.

5 Mirá ver de alegrarvos y también enboracharvos y de el probe apiadavos, contentaldo en Purim.

Hamán fue.

\footnotetext{
${ }^{8}$ [N. E.-Escrito אמאן ג'יקירונייא, cuya primera palabra debe tratarse de tc. aman 'ipor Dios!, igracias a Dios!', y la segunda quizás haya que ponerla en relación con tc. çek- que en slang significa 'beber'.]

9 Según Joseph Nehama, Dictionaire du judéo-espagnol (Madrid: CSIC, 1977) s.v. apuntár, -se: 'se goumer, se guinder', es decir, 'darse tono, hacerse los estirados'. 
6 Muncho mal mos quis̀o haćer este Hamán el mamćer, por esto hacéš plaćer de quemarlo en Purim. Hamán fue.

7 Tomí péndola en mi mano por quemalde yivo y sano a Hamán hijo de un aśno cada día de Purim.

Hamán fue.

8 Súpito lo combidaron, la cabeza le abocaron, con los hijos lo enforcaron en día antes de Purim.

Hamán fue.

9 Esto no se quere dicho que vaš a sentir mi dicho: a Mordejay el bendicho bendećildo en Purim. Hamán fue.

[25b] 10 Mirá ver de haćer toca con los vaśos a la boca, también a Źeréš la loca maldećilda en Purim. Hamán fue.

11 No se quere encomendado por mercar de el buen pešcado y que sea bien guiśado por kabod de Purim.

Hamán fue.

12 La gallina la más godra mercaréš en esta hora, no miréš parás agora en el gaste de Purim. Hamán fue.

13 Carne muncha tomaréš, frita y asada la haréš 
y con vino beberéš

el día entero de Purim.

Hamán fue.

14 Traé vino con bocales porque ganen los amales, a Hamán todos los males le vino en día de Purim. Hamán fue.

15 Si jugaréš a los dados de reyir que no quede lados, los pedridos y los ganados se enborachen en Purim.

Hamán fue.

16 Ganar y meter al pecho no es esto lo derecho, a la meaná en derecho traé vino para Purim. Hamán fue.

17 Chico y grande bayilaréš y los vaśos henchiréš y con gusto beberéš muncho vino en Purim.

Hamán fue.

*18 En lo que estáš bebiendo sin tener dingún miedo entre mientes yir dićiendo arur Hamán en Purim. Hamán fue.

19 Si la hora me ayudaba más complas aresentaba, la yacá no le soltaba de quemaldo en Purim. Hamán fue.

20 Por esto me pedronéš, por mí un vaśo bebréš, con yoź alta cantaréš estas complas de Purim.

Hamán fue.

21 Cada año mejorado, źera' de 'Amalec arematado mos mandará al untado en este día de Purim

Hamán fue. 
El texto que ofrezco es el resultado de mi edición crítica, proyectada en todos los casos menos uno (creo) no en lo que serían correcciones propiamente textuales sino enmiendas de lo que parecen ser yerros de tipógrafo (frecuentes, por otra parte, en las ediciones del «sefardí» - por contagio quizás-Zuckerman). Así en lo consonántico, he suplido la ausente tilde de fricación en la pe/fe (enporcado por enforcado [1Eb] у pue por fue [E en todas sus veintiuna ocurrencias]), y en la bet/vet (probe [5c] y cabeza [8b] con $b$ oclusiva por las mismas con labial fricativa), y la de palatalidad en źayin/žayin (anośen por anojen [4b]). Y en lo vocálico, he suplido los grafemas vocálicos ausentes (álef en $m[a]$ ravilla [1c], vav en $f[\boldsymbol{u}]$ [ [1Ea], y yod en bendeć $[\boldsymbol{i}] l d o[9 \mathrm{~d}]$ y en p[e]dronés [20a]), y he corregido alguno malamente puesto (juduriya por juderiya [1b] cambiando por yod la vav). Por último, he restaurado la perdida concordancia cambiando todos la judiós queridos (2b), probablemente lapsus de tipógrafo pensando en 'toda la judería', por el esperable todos los judiós queridos. Me he abstenido de corregir bebréš (20a) porque no me parece imposible tal forma sincopada alternando con la regular beberéš (passim).

Rasgos lingüísticos notables hay bien pocos que señalar: quizás los únicos sean la alternancia del imperativo plural apocopado (Mirá 5a 19a, Traé 14a 16d) con la plena con - $d$ final, que aparece siempre metatizada con la $l$ - inicial del afijo pronominal (contentaldo $5 \mathrm{~d}$, bendećildo $9 \mathrm{c}$, maldećilda 10d); y junto a ella, la extensión analógica de la metátesis del imperativo al infinitivo (quemalde 7b, quemaldo 19d) aunque no en todos los casos (quemarlo 6d).

En cuanto al léxico, me parece notable la forma «los perdidos y los ganados» (15c) referida no a los dineros sino a 'quienes han perdido' y a 'quienes han ganado' en el juego; que me parece comparable a la preciosa parida no para 'la criatura que ha sido parida' sino para 'la mujer que ha parido', y por extensión, el parido no para 'el niño que ha sido parido' sino para 'el hombre que «ha parido»', es decir, 'el que le ha engendrado la criatura a la parida'. Otras expresiones como «hacer toca» (10a), 'brindar (chocando los vasos)', «la estrella le cayó» (3c), «de reyir que no quede lados» 'partirse de risa' son castizas y están de sobra documentadas.

En la poética lo más notable -por ser el texto de fecha tan tardía- es la aparición de rima silábica en la estrófica mano / sano / aśno (7a-c): no olvidemos que la rima silábica es uno de los recursos más castizos de las coplas, pero que es frecuentísimo en las antiguas mientras que va haciéndose cada vez más raro en las modernas.

Sobre realia, usos y costumbres de Purim encontramos varios testimonios: al monigote de Amán no puede saberse si se lo quemaba (5c 7b 19d) como en tiempo antiguo (y causa de calumnia ritual llegó a ser alguna vez), o si el escri- 
birle y cantarle una copla era entonces una vía sustitutoria de la problemática quema. El vino hay que traerlo «con bocales» para que así los «amales» hallen qué ganar (14b). Está mal visto «meter al pecho» ('echarse al bolsillo' 16a) lo que pueda uno ganar en el juego: lo «decente» es ir «a la meaná en derecho» (16c) a gastárselo en vino (16d). Y como resumen, ser pródigo: «no miréš parás agora / en el gaste de Purim» (12c-d) para gastar en buenas comidas, desde luego (11b-c 12a-c 13a-b), pero sobre todo para beber vino hasta la embriaguez (5b 10a-b 13c 14a 15d 16c-d 17b-d 18a y hasta 20b): de ahí el nombre La bebienda de Purim que he preferido para la copla. Lo único incongruente que encuentro en la copla es que haya que «yir dićiendo / arur Hamán» (18c-d), cuando para cumplir puntualmente el precepto de «'ad delá yadá'» ('hasta que no sepa') tendría que haber dicho «baruj Hamán» (y «arur Mordejay») ${ }^{10}$.

${ }^{10}$ [N. E.- El autor editó este texto sin las marcas diacríticas usadas para marcar las diferencias fonéticas entre el judeoespañol y el español actual; las he restaurado para atenerme el sistema de la revista Sefarad. No quiero, sin embargo, omitir el alegato final de su texto en el que Hassán argumentaba lo innecesario del uso de tales marcas para el conocedor del judeoespañol, opinión que comparto totalmente. Esto es lo que decía al respecto:] «Para terminar: me reprochan ácidamente los actuales militantes del arevivimiento del ladino -y sus corifeos del campo académico- que use para los textos en ladino una ortografía basada en la hispánica porque de este modo diz que los desladinizo y los convierto en españoles. Mentira. Creo haber mostrado con esta edición que el texto no es menos ladino por no haberlo presentado con una escrupulosa transliteración de la aljamía hebraica ni mucho menos con la bárbara ortografía que usan los arevividores residuales de hoy para popularizar sus textos, sino que la ortografía hispánica es tan apta como la grafémica, la fonémica, la fonética (y no digamos la seudofonética); pues de los sonidos que no tienen representación en la ortografía normativa porque no existen en el sistema fonólogico del español actual, ¿quién no sabe que es palatal la -s(- final de los verbos bailarés, beb(e)rés, cantarés, hacés, harés, henchirés, jugarés, mercarés, mirés, pedronés y tomarés y la medial y final de los nombres pescado y Zeres; que es alveolar sonora la -s- de guisado, vaso(s) y por supuesto asno; que el mismo fonema alveolar sonoro lo representan la -c- de bendecildo, diciendo, hacer, hacés, maldecilda, mamcer, placer, vecinos y la -z-de hizo y Zeres; que es prepalatal sonora fricativa la -j-de anojen, hijos, mejorado y quijo y africada la de ajunten, juderi(y)a, judió y jugarés; que es oclusiva la -bintervocálica de abocaron (la $v$ - de voz lo sería en cualquier caso por fonética sintáctica)? Quien no lo sepa y necesita que le barbaricen la ortografía, ese... no tiene vela en este entierro (y lo digo sin ninguna aviesa intención) y más vale que se calle la boca». 


\section{Glosario}

'Amalec (hb. עמלק): vid. źera '.- amales (tc. sing. hamal) 'cargadores, porteadores'.-- apuntarse: vid. nota 8.- arur (hb. ארור) 'maldito'.- kabod (hb. כבוד) 'honor'.- mamćer (hb. ממזר) 'bastardo'.- meaná (tc. meyhane) 'taberna'.- nes (hb. נס) 'milagro'.- parás (tc. sing. para) 'monedas, dinero'.- untado 'ungido', se refiere al mesías.- yacá (tc. yaka) 'cuello (de un vestido)'.-_źera' (hb. זרע 'simiente, estirpe'): — de 'Amalec 'amalecita'.

\section{RESUMEN}

En el presente artículo (postumo y editado por Elena Romero) se determina el corpus clásico de las coplas de Purim del «ciclo de la reina Ester», aludiendo a su estrofismo, autores y problemática de las ediciones y su difusión; asimismo se avanza en la determinación del corpus de las coplas de Purim llamadas «novísimas». Finalmente se lleva a cabo la edición de una copla del primer grupo hasta ahora desconocida: La bebienda de Purim.

PAlabras Clave: Literatura sefardí; Coplas; Purim; Bibliografía de coplas sefardíes; Edición de textos.

\section{SUMMARY}

In this posthumous article (edited by Elena Romero), the author tries to determine the classical corpus of the Purim "Coplas" of the Queen Esther cycle, refering to their strophical structure, their authors and the problems of edition and diffusion. Likewise, this study represents a significant step in the establishment of a corpus of Purim "Coplas" known as "novísimas." An edition is presented here of an hitherto unknown "Copla" belonging to the first group: La bebienda de Purim.

Keywords: Sephardic Literature; "Coplas"; Purim; Sephardic "Coplas” Bibliography; editions of texts. 